\title{
NOTES ON TRANSCRIPTION AND TRANSLATION
}

\section{TRANSCRIPTION DILEMMAS}

In the matter of transcription, I have, except where noted, transcribed all of the texts from the original or a photocopy of the original. As to the actual letters of the words, I have great faith in the transcriptions. The calligraphy of older Maya texts is in general readily legible. The transcriber does, however, face three central problems. First, the varying phonetic repertoires of Maya and Spanish provided the indigenous writers doing the texts with some challenges. In writing Spanish words, they would often change letters, leaving out the letter for a sound not in Maya and putting in the letter for its closest approximation in their own repertoire. Since the Maya heard no difference between sounds they had and sounds they lacked, they were prone to write some of the letters signifying exotic sounds even for their own sounds, a process often called hypercorrection, as in writing fel for pel, "vagina," even though Maya had $p$ and lacked $f$. As a result, Spanish words are sometimes hard to recognize in Maya texts, and without the support of a recognizable root, one may even read the letters wrong.

A second issue for the transcriber is the fact that the Maya were not consistent in their manner of dividing strings of letters. In some sections of a text there may be spaces between the words almost as in modern writings. In another section the spaces may be in the middle of words. To this day, word division in Maya writing is not fully standardized. Since Maya roots generally are constructed on the model of consonant-vowel-consonant, I can usually 
discern the roots, distinguishing them from the set of affixes associated with them, and thus arrive with some certainty at the words.

A third problem is that older Maya texts had no punctuation, making it difficult for the transcriber to figure out where an utterance begins and ends. In several cases I have transcribed passages differently from Munro Edmonson because of these last two issues. We find different boundaries for words and put the beginning and ending of certain passages at different places.

In my transcriptions I have attempted to be as faithful as possible to the originals. I have followed standard formats for these types of transcriptions in ethnohistorical texts, placing the transcriptions next to the translations. I have allowed the text to run on in the original format, dividing it only where necessary for the reader to be able to follow the relationship between the transcription and translation. I have written glottalized consonants as the Maya wrote them, with a strike-through feature, as follows: $c$, $\not$. The Maya wrote the glottalized $t s$ as a backwards $c$, and I have reproduced this convention. In some cases, the glottalized consonants were written as double consonants, such as $p p$. The glottalized $t$ most often was written as $t h$. The Maya term yetel, "and," most often was written as $¥$.

\section{THE ACT OF TRANSLATION}

I must note that the translations of the documents, while generally very strong and always justifiable, are somewhat tentative. While all of the relevant translations related to the human body, gender, and sexual acts are extremely solid, some of the broader translations are based more on interpretation of the language. Wherever I have questions about the translations, I have provided the reader with a note explaining the circumstances. Except where otherwise noted, I have translated all of the documents myself in order to give the most accurate translations possible. However, in all cases I have compared my translations to those of other scholars, and in some cases I have rectified my translations accordingly. As the texts that I use are extremely complex, there is no way to provide complete definitive translations at this time.

Throughout this manuscript I have attempted to provide the reader with the most accurate possible transcriptions and translations of the Maya language texts. I have put a major effort into the task, working over the texts repeatedly, and I have consulted all known previous translations. Nevertheless, translating colonial Maya documents into English is a tricky affair. Work with the hieroglyphic writing and with the modern spoken language is perhaps 
more advanced for Maya than for any other Mesoamerican language family, but the same is not true of philology based on texts set down in alphabetic script in the centuries after the conquest. Scholars hardly know the general grammar of those times, much less the specific grammars of the genres in which the writing was done. William Hanks has pointed out some grammatical deficiencies in translations done to date, ${ }^{1}$ but even when translators are aware of the problem, they cannot always easily overcome it. The obscurity extends to the vocabulary itself. Some of the documents studied in this work, particularly the Books of Chilam Balam and the Ritual of the Bacabs, are quite arcane, using some words found in no dictionary and others in senses not otherwise attested. Their language is extremely complex and metaphorical, consciously veiled. I have no doubt that much further progress will be made in the translation of these and other older Maya texts and that as that process goes on, it will be seen that I have committed some errors of translation. I have, however, done everything I could, and I present the versions here as at least comparable in quality to others that have been published. Throughout, I have tried to remain aware of the uncertainties. Indeed, I have omitted some very interesting texts because sufficient certainty could not be attained. When I am aware of problems in passages of my own translations, I have discussed them in the endnotes. In a few cases a particular word or line has baffled me to such an extent that I have used another scholar's translation as a last resort. Such instances are always noted. I have given maximum attention to accuracy in matters of the central terminology related to the body, gender, and sexual desire.

Of the grammatical problems I have faced, I have been especially aware of those related to the possession of nouns. ${ }^{2}$ Maya uses possessive prefixes profusely. In the texts it is often by no means obvious to whom or to what the prefix refers, and in some cases no candidate for the possessor is on the textual horizon at all. The texts reduce the indication of the possessor to a minimum, writing $y$ - for $u y$-, "his/her/its, their," and leaving out the -ob plural more often than not even when the possessor is both plural and animate. Only the context can determine the number of the possessor and in some cases even the person. Hence there are many uncertainties involved in identifying the referent of a possessive prefix.

Another problem I have faced repeatedly is the large number of verbal roots without inflection in the texts. Some can be accounted for as preterits, imperatives, hypothetical or unrealized forms, or even interpreted nominally, but there still seem to be too many of them, and they are very hard to inter- 
pret. I cannot avoid the feeling that verbal inflection, especially temporal marking, as it appears in older written Maya, does not correspond very well with the descriptions found in the Maya grammatical texts. ${ }^{3}$

At the level of syntax and stylistics, the issues are many. Munro Edmonson states that the couplet is the primary device used in the Books of Chilam Balam. ${ }^{4}$ Hanks does not share Edmonson's opinion, ${ }^{5}$ and I have shown above that the Maya used many other devices in their writing. One's opinion on this matter affects translation substantially. 
FROM MOON GODDESSES TO VIRGINS 
THIS PAGE INTENTIONALLY LEFT BLANK 